\title{
Application of COMPOCHIP Microarray to Investigate the Bacterial Communities of Different Composts
}

\author{
Ingrid H. Franke-Whittle • Brigitte A. Knapp • \\ Jacques Fuchs $・$ Ruediger Kaufmann • Heribert Insam
}

Received: 7 January 2008 / Accepted: 31 July 2008 / Published online: 26 September 2008

(C) Springer Science + Business Media, LLC 2008

\begin{abstract}
A microarray spotted with 369 different 16S rRNA gene probes specific to microorganisms involved in the degradation process of organic waste during composting was developed. The microarray was tested with pure cultures, and of the 30,258 individual probe-target hybridization reactions performed, there were only 188 false positive $(0.62 \%)$ and 22 false negative signals $(0.07 \%)$. Labeled target DNA was prepared by polymerase chain reaction amplification of $16 \mathrm{~S}$ rRNA genes using a Cy5-labeled universal bacterial forward primer and a universal reverse primer. The COMPOCHIP microarray was applied to three different compost types (green compost, manure mix compost, and anaerobic digestate compost) of different maturity ( 2,8 , and 16 weeks), and differences in the microorganisms in the three compost types and maturity stages were observed. Multivariate analysis showed that the bacterial composition of the three composts was different at the beginning of the composting process and became more similar upon maturation. Certain probes (targeting Sphingobacterium, Actinomyces, Xylella/Xanthomonas/
\end{abstract}

Electronic supplementary material The online version of this article (doi:10.1007/s00248-008-9435-2) contains supplementary material, which is available to authorized users.

I. H. Franke-Whittle $(\bowtie) \cdot$ B. A. Knapp · H. Insam Institute of Microbiology, Leopold-Franzens-Universität,

Technikerstrasse $25 \mathrm{~d}$,

6020 Innsbruck, Austria

e-mail: ingrid.whittle@uibk.ac.at

J. Fuchs

Forschungsinstitut für Biologischen Landbau (FIBL),

Frick, Switzerland

R. Kaufmann

Institute for Ecology, Leopold-Franzens-Universität,

Innsbruck, Austria
Stenotrophomonas, Microbacterium, Verrucomicrobia, Planctomycetes, Low $\mathrm{G}+\mathrm{C}$ and Alphaproteobacteria) were more influential in discriminating between different composts. Results from denaturing gradient gel electrophoresis supported those of microarray analysis. This study showed that the COMPOCHIP array is a suitable tool to study bacterial communities in composts.

\section{Introduction}

The biological process of composting involves the complete or partial degradation of organic materials by a consortium of microorganisms, the composition of which changes as the composting process progresses. Relatively little is known about the microorganisms involved and their exact activities in the different phases of the composting process. A typical composting procedure comprises a series of different temperature stages, which are known to be associated with specific populations of bacteria and fungi $[7,14]$. Continual change in the environmental conditions in composts (temperature, $\mathrm{pH}$, aeration, moisture, and availability of substrates) results in different stages of exponential growth and stationary phases for different organisms. Knowledge on the diversity and dynamics of the microbial communities of compost is increasing rapidly through the use of molecular biology tools such as community fingerprinting by amplified rDNA restriction analysis, denaturing gradient gel electrophoresis (DGGE), and DNA hybridization techniques [1, 22, 40, 47].

Nucleic acid microarrays offer the possibility to analyze a specifically selected array of microorganisms, concerning their presence or absence in a particular environmental sample, in a single experiment [9]. Microarray technology has been applied successfully to study microbial commu- 
nities in several habitats such as municipal wastewater [29], landfill methanotroph communities [43], and trinitrotoluenecontaminated soils [17]. Clone library studies and metagenome approaches like pyrosequencing yield information beyond the cultivated part of the community; however, these techniques involve much work and are expensive. In an accompanying study with composts [13], we were able to demonstrate that the COMPOCHIP microarray supported the results of cloning.

A microarray specific for compost microorganisms would allow for the quick detection of many different microorganisms in a single test and thus for the fine-tuning of production processes. Specific qualities of the endproduct could thus be obtained, such as the absence of pathogens, the presence of beneficial microorganisms, or plant disease suppressiveness. An improperly managed composting process can allow the survival, proliferation, and spread of animal, human, and plant pathogens $[6,16]$. The detection of pathogens using the microarray could alert compost producers to the presence of these organisms, although confirmation by traditional methods would also be required. Plant disease suppressiveness is among the most important features of high quality composts, and composts can help in the control of several important soil-borne pathogens of crops $[20,26]$. In most cases, these effects are attributed to the presence of beneficial microbes in the compost.

A microarray would also allow the differentiation between compost samples according to their bacterial communities. In previous publications [18, 19], we described the development and optimization of a compost microarray that included 65 probes targeting plant, animal, and human pathogens, as well as microorganisms that had been previously reported in the composting process. In this study, we describe the further design and validation of the 16S rRNA-gene based COMPOCHIP microarray and its first application to different types of composts and compare the results with those obtained by polymerase chain reaction (PCR)-DGGE.

\section{Materials and Methods}

\section{Source of Bacterial Strains}

Reference strains for specificity validation of the microarray oligonucleotide probes were obtained from the German Collection of Microorganisms and Cell Cultures (DSMZ), from the culture collection at the Institute of Microbiology, University of Innsbruck, and from the Austrian Agency for Health and Food Safety. Cultivation conditions for organisms were as suggested by the DSMZ or according to their references.

\section{Collection of Compost Samples}

Compost samples used in this study were collected from the composting plants in Oensingen and Fehraltorf, Switzerland. Samples of all three composts were collected at 2, 8, and 16 weeks. The green compost (CH-Oensingen) comprised $35 \%$ tree cuttings, $20 \%$ lawn clippings, $38 \%$ green clippings, 3-4\% soil, and 3-4\% cereal processing residues. The manure mix compost (CH-Fehraltorf) comprised $25 \%$ horse manure, $10 \%$ mature compost, $50 \%$ green clippings, $10 \%$ soil, and $5 \%$ cereal processing residues. The anaerobic digestate compost (CH-Oetwil am See) was formed from green waste, kitchen waste, and food residues that were digested for 12 days in an anaerobic digester, dewatered and then composted in Fehraltorf. The green compost had $\mathrm{pH}$ values of $8.1,9.1$, and 8.5 at weeks 2,8 , and 16 , and the composting process reached a temperature maximum of $71{ }^{\circ} \mathrm{C}$ (for 8 days, the temperature was $>60^{\circ} \mathrm{C}$ ). The manure mix compost had $\mathrm{pH}$ values of $7.5,8.5$, and 8.2 at weeks 2,8 , and 16 , and the composting process reached a temperature maximum of $65^{\circ} \mathrm{C}$ (for 31 days, the temperature was $>60^{\circ} \mathrm{C}$ ). The anaerobic digestate compost had $\mathrm{pH}$ values of $8.1,8.4$, and 8.4 at weeks 2,8 , and 16 , and the composting process reached a temperature maximum of $68^{\circ} \mathrm{C}$ (for 14 days, the temperature was $>60^{\circ} \mathrm{C}$ ).

Windrows (3.4-m width, $1.8-\mathrm{m}$ height) were turned every 2-3 days with a self-propelled Sandberger (Neuson Hydraulic, Linz, Austria) turner, and immediately prior to sampling, windrows were turned at least twice. Humidity was manually controlled before each turning operation, and, if needed, water was added during the turning operation. A profile was dug into each of the compost windrows, and approximately every $3 \mathrm{~m}$, a $10-\mathrm{cm}$ "slice" of the windrow was sampled and placed into an aluminum container. After thorough mixing of the ten 601 subsamples, 500-g samples were collected and sent directly to the laboratory for molecular analysis. One composite sample was available for each compost type and sampling time.

\section{DNA Extraction}

DNA was extracted from bulk compost samples using a procedure described previously [19]. A Promega Wizard DNA clean up kit (Madison, WI, USA) was used to purify DNA, according to the instructions of the manufacturer. Extracted DNA was subjected to electrophoresis in a $1 \%$ agarose gel in $1 \times$ Tris-acetate-EDTA (TAE) buffer, and DNA concentration was determined by fluorescence using a PicoGreen ${ }^{\circledR}$ dsDNA quantitation kit (Molecular Probes, Oregon, USA) and a fmax Fluorescence Microplate Reader (Molecular Devices, CA, USA), as described by the manufacturer. 
Design and Evaluation of Oligonucleotide Probes

Oligonucleotide probes were designed with the ARB software package [34] using the PROBE FUNCTIONS tool and the PROBE_MATCH tool for specificity testing. All possible probe mismatches to non-target organisms were centralized to minimize the risk of unspecific binding [49]. The GeneRunner program (http://www.generunner. com) was used to calculate the $\mathrm{GC} \%$-content, predicted melting temperature, and formation of secondary structures. Sequences were subjected to a basic local alignment search tool analysis [3], and further evaluation of the specified probe sequences was done by searching for matches between the probe and its potential targets within the rRNA sequences in the RDP II database. The Probebase on line resource for rRNA-targeted oligonucleotide probes was used as a tool to search for already published probes to be included in the study [32]. A table provided in the Electronic supplementary material lists the sequence, specificity, and predicted melting temperature of all probes. Probe names were based on the nomenclature of Alm et al. [2].

\section{Microarray Manufacture and Processing}

Oligonucleotide probes for microarray printing were synthesized by ThermoHybaid (Ulm, Germany), and the $5^{\prime}$ end of probes was tailed with 12 2'-deoxythymidine 5'triphosphate molecules (T-spacer). Microarrays were printed by Lambda GmbH (Freistadt, Austria). To allow covalent coupling of oligonucleotide probes to the aldehyde-coated CSS-100 glass microscope slides (Genetix $\mathrm{GmbH}$, München, Germany), the 5'-terminal nucleotide of each oligonucleotide was amino modified with C 6 MMT.

Lyophilized oligonucleotides were resuspended in water and diluted to a printing concentration of $23 \mu \mathrm{M}$ with $3 \times$ saline-sodium citrate (SSC) buffer prior to spotting onto the activated slide surface using a Piezo-printer (GeSim Nano-Plotter NP 1.2) with a "NanoTip" micropipetting tip. A volume of $0.3-0.4 \mathrm{nl}$ of each probe was spotted in duplicate on slides. Quality controls were printed as single spots on the left and right sides of each row of the microarray, and hybridization controls were printed in the middle of each row.

Preparation of Fluorescently Labeled Target DNAs by PCR

Labeled target DNA was prepared by PCR amplification of 16S rRNA genes using a Cy5-labeled universal bacterial $8 \mathrm{~F}$ forward primer. Briefly, target DNA from reference strains and compost DNA samples was subjected to PCR amplification of the nearly complete $16 \mathrm{~S}$ rRNA genes with the universal bacterial primers $8 \mathrm{~F}$ (AGAGTTTGATCMTGG), to which a Cy5-label was attached at the 5' end, and 1492R
(TACCTTGTTACGACTT), to which a $\mathrm{PO}_{4}$-group was conjugated at the $5^{\prime}$ end [11]. PCR amplifications were performed in a ThermoHybaid PCR Express thermalcycler in 50- $\mu$ l volumes, with each standard reaction mix containing a final concentration of $1 \times$ reaction buffer $[16 \mathrm{mM}$ $\left(\mathrm{NH}_{4}\right)_{2} \mathrm{SO}_{4}, 67 \mathrm{mM}$ Tris- $\mathrm{HCl} \mathrm{pH} 8.8,1.5 \mathrm{mM} \mathrm{MgCl} 2$, $0.01 \%$ Tween 20] (GeneCraft, Münster, Germany), $200 \mu \mathrm{M}$ each deoxyribonucleotide triphosphate (dNTP), $0.8 \mu \mathrm{M}$ of the forward primer, $0.2 \mu \mathrm{M}$ of the reverse primer, $1 \times$ enhancer (Peqlab, Germany), 1.25 U BioTherm ${ }^{\text {TM }}$ DNA polymerase (GeneCraft, Münster, Germany), and sterile water. In addition, $10 \mathrm{mM}$ tetramethylammonium chloride was included in reactions to enhance the specificity [33]. Five microliters of extracted compost DNA (diluted 1/60) was applied directly to the PCR reaction mix.

Thermal cycling was performed according to [37]. After an initial denaturation at $95^{\circ} \mathrm{C}$ for $5 \mathrm{~min}$, amplification reactions were subjected to $10 \mathrm{~min}$ at $80^{\circ} \mathrm{C}, 1 \mathrm{~min}$ at $50^{\circ} \mathrm{C}$, and $3 \mathrm{~min}$ at $72^{\circ} \mathrm{C}$. Thermal cycling then proceeded with 33 cycles of $95^{\circ} \mathrm{C}$ for $1 \mathrm{~min}, 50^{\circ} \mathrm{C}$ for $1 \mathrm{~min}$, and $72^{\circ} \mathrm{C}$ for 3 min. Temperature cycling was followed by a final extension at $72^{\circ} \mathrm{C}$ for $10 \mathrm{~min}$. PCR products $(100 \mu \mathrm{l})$ were purified with the GenElute ${ }^{\mathrm{TM}}$ PCR Clean-Up Kit (Sigma, Missouri, USA). For the subsequent preparation of fluorescently labeled single-stranded DNA targets, the phosphorylated DNA strand was removed. One thousand nanograms of a purified PCR product was digested using 30 U Lambda exonuclease (Epicentre, Madison, WI, USA) in $1 \times$ Lambda exonuclease buffer, at $37^{\circ} \mathrm{C}$ for $3 \mathrm{~h}$.

\section{Hybridization}

Single-stranded Cy5-labeled PCR product (500 ng) was vacuum-dried and resuspended in $20 \mu \mathrm{l}$ of a hybridization buffer consisting of $5 \times \mathrm{SSC}, 1 \%$ blocking reagent (Roche, Mannheim, Germany), $0.02 \%$ sodium dodecyl sulfate (SDS), $0.1 \% n$-laurylsarcosine, and 5\% formamide [33]. One microliter of a 50-nM Cy5-labeled control oligonucleotide (Electronic supplementary material, Table 1) was added to each tube, and the mixture was denatured for $10 \mathrm{~min}$ at $95^{\circ} \mathrm{C}$, before being placed on ice. Nineteen microliters was transferred onto a prechilled microarray (on ice) and covered with a glass coverslip to guarantee a uniform moistening of the array surface, and arrays were placed into small plastic containers with hybridization buffer saturated blotting paper for equilibration. Hybridization was conducted at $56^{\circ} \mathrm{C}$ for $4 \mathrm{~h}$. After hybridization, slides were washed immediately at room temperature, each for $3 \mathrm{~min}$ in buffer $1(1 \times \mathrm{SSC}, 0.2 \% \mathrm{SDS})$, followed by buffer $2(0.01 \times \mathrm{SSC}, 0.2 \% \mathrm{SDS})$ and buffer $3(0.05 \times \mathrm{SSC})$. Finally, arrays were briefly submerged into distilled water and air-dried. Array experiments were conducted in triplicate. 
Scanning of Arrays and Image Analysis

Microarray slides were scanned with a ScanArray Gx microarray scanner (Perkin Elmer, Massachusetts, USA). Scan power was set to $90 \%$ and PMT gain to 500 $(635 \mathrm{~nm})$ and $450(532 \mathrm{~nm})$ for scanning. Fluorescent images were analyzed using the ScanArray Gx software (Perkin Elmer) by superimposing a grid of circles onto the image to designate each fluorescent spot to be quantified. The median foreground and background signals for all spots were determined. The signal-to-noise ratio (SNR) for all spots was calculated according to the following calculation:

$\mathrm{SNR}=\left[\begin{array}{l}\text { median foreground of probe }- \\ \left(\begin{array}{l}\text { median foreground of nonsense } \\ \text { probe KO 19 }- \text { median background } \\ \text { of nonsense probe KO 19 }\end{array}\right)\end{array}\right) /$ median background of probe

Signals were assumed to be positive if a SNR value of $\geq 2$ was obtained [33]. Statistical analyses of data were performed using the program Canoco 4.5 [46]. Probes were sorted by the maximum SNR for all samples, and of the 369 probes on the COMPOCHIP microarray, 102 probes had a maximum SNR above 2, and were thus included in the analyses. Because a strong correlation between standard deviation and means of replicate samples was found, a logtransformation of data was conducted to equalize variances. Covariance based redundancy analysis (RDA), a canonical form of principal component analysis, was used for data analysis, and the canonical variables were compost type and time. RDA used the following settings: inter-sample distance scaling, no post-transformation of scores, log data transformation (no offset), and center by species.

\section{PCR and DGGE}

DNA for DGGE analysis was amplified with the primer set 338fGC-907r [35, 41]. Each PCR mixture contained $0.5 \mathrm{ng}$ of extracted DNA, $0.2 \mu \mathrm{M}$ of each primer, $1.25 \mathrm{U}$ Bio Therm ${ }^{\mathrm{TM}}$ DNA Polymerase (Gene Craft), $1 \times$ DNA polymerase buffer $\left[16 \mathrm{mM}\left(\mathrm{NH}_{4}\right)_{2} \mathrm{SO}_{4}, 67 \mathrm{mM}\right.$ Tris- $\mathrm{HCl}$ $\mathrm{pH} 8.8,1.5 \mathrm{mM} \mathrm{MgCl} 2,0.01 \%$ Tween 20], $0.1 \mu \mathrm{g} \mu \mathrm{l}^{-1}$ bovine serum albumin, 4\% $(v / v)$ dimethylsulfoxide, $200 \mu \mathrm{M}$ each $\mathrm{dNTP}$, and $2.5 \mathrm{mM} \mathrm{MgCl} \mathrm{M}_{2}$ in a final volume of $25 \mu \mathrm{l}$.

DGGE was performed using the Ingeny PhorU2 system (Ingeny International BV, The Netherlands). PCR products $(60 \mathrm{ng})$ were loaded into the wells of a $7 \%(w / v)$ polyacrylamide gel with a denaturing gradient of $40 \%$ to $70 \%(100 \%$ denaturant consists of $7 \mathrm{M}$ urea plus $40 \%$ formamide in $1 \times$ TAE buffer), and each gel was run for $16 \mathrm{~h}$ at $100 \mathrm{~V}$ at a constant temperature of $60^{\circ} \mathrm{C}$ in $1 \times \mathrm{TAE}$ buffer ( $\mathrm{pH}$ 7.4). After electrophoresis, gels were stained with silver nitrate using an automated gel stainer (Amersham Pharmacia Biotech, Germany), photographed and airdried. DGGE banding patterns were analyzed using the GelCompar II version 4.0 software package (Applied Maths, Ghent, Belgium). A matrix of similarities was calculated based on the Dice correlation coefficient, and dendrograms were constructed using the algorithm of Ward [30].

\section{Results and Discussion}

\section{Probe Design}

In our previous microarray publication, we described the methodological development of a set of 65 probes specific for microorganisms involved in the composting process [19]. This initial probe set has been extended to include 369 probes, following a multiple-probe approach. Probes targeting organisms commonly found in soils and composts have been included, and the microarray can be applied to different environmental samples. Ideally, all probes in a set of probes that perfectly match a target organism should hybridize in order to reduce the risk of a false-positive identification of the target. For most target organisms, at least three probes were spotted on the slide, and only for a few organisms were there two probes (Electronic supplementary material, Table 1). In order for a target to be considered present in a sample, more than one probe specific for the target needed to yield a SNR above the detection limit. Probes were designed to target at either the phylum, family, genus, or species level. Because of the high level of sequence conservation of the 16S rRNA gene between phylogenetically related bacteria, it was not always possible to design a probe specific to only a particular species. Therefore, some probes were designed that targeted two or more members of a genus (Electronic supplementary material, Table 1). Due to the fact that all the probes on a microarray are subjected to the same conditions of hybridization, probe design can be a difficult process requiring much optimization, with the maximization of probe sensitivity and specificity very often being conflicting goals. All the probes included on the COMPO CHIP microarray were designed so to have similar melting temperatures, and probe sequences ranged in length from 17 to 25 nucleotides (Electronic supplementary material, Table 1). The $T_{\mathrm{m}}$ for the different probes varied from 55.9$63.7^{\circ} \mathrm{C}$ (calculated according to the nearest neighbor model) [10], and it was not possible to further narrow this due to the limited number of differential sequence regions in the 16S rRNA gene. As a result, probes with suboptimal predicted melting temperatures were included if no alternatives were available. 
Probe design was conducted so that mismatches were as centrally located within oligonucleotide sequences as possible. Single mismatches in the end positions were not considered as differences, as mismatch positions near, or at the terminus of a short duplex are reportedly less destabilizing than internal mismatches [42]. Prior to probe synthesis, secondary structure formations were also studied. Oligonucleotides with strong hairpin structures, dimers, internal loop, or bulge loop formations were considered suboptimal and were not included if other possible probes could be designed. We considered secondary structures with $\mathrm{dG}$ values $\leq$ approximately -3 , as stable [50] (C. Hoebartner, personal communication).

\section{COMPOCHIP Specificity Validation}

The specificity of all probes was assessed in silico, using the ARB program. However, the results obtained in silico and obtained upon microarray hybridization can differ; thus, the specificity of a majority of the oligonucleotide probes included on the array were tested with pure cultures. Due to reasons of restricted distribution of high-risk group biological agents and difficulty in cultivation, not all pure culture microorganisms were available to check probe specificities. Of the 369 probes included on the array, 67 of the probes were not validated. Of the 302 probes that were validated, 213 probes $(71 \%)$ were found to hybridize exclusively to their target organisms (Electronic supplementary material, Table 1). Of the 30,258 individual probetarget hybridization reactions performed (hybridization of 82 reference microorganisms), there were only 22 falsenegative signals $(0.07 \%)$ and 188 false-positive signals seen $(0.62 \%)$. These hybridization results are statistically similar to those obtained by other authors [8, 33, 39]. Certain probes were found to bind non-specifically with several targets, these probes being the Alphaproteobacteria KO 240 (9), Low G+C KO 319 (17), Nitrospira KO 295 (7), Thermomonospora chromogena KO 330 (7), and Actinomyces KO 342 (6). Other probes also bound non-specifically to one or a few of the target DNAs. This happened despite the fact that there existed a varying number of mismatches between target and probe sequences. For example, the Burkholderia probe KO 234 was found to hybridize with Saccharomonospora DNA, despite six basepair differences in the probe target sequence, and Clostridium bifermentans DNA hybridized with the Clostridium butyricum KO 377 probe, despite ten mismatches in the probe target sequence. Because microarray experiments use the one set of conditions for hybridization and washing, false positives are not an uncommon event [33]. Both cultured and uncultured/unknown microorganisms can cause the generation of false-positive signals. One approach that can be used to guarantee the reliability of microarray results is to include several probes with identical specificities for each target species or group. Using this approach, all probes in a set of probes matching the target microorganism must show positive hybridization signals to avoid the risk of false-positive identification [33]. This approach has been used in our study.

Probes that did not show a positive hybridization signal with the target reference microorganisms $(6 \%$ of all designed probes) were excluded from the analysis and will be excluded from the microarray in future experiments. False-negative signals are a common phenomenon in microbial microarray analysis $[28,33]$ and can be explained by parameters such as secondary structures in the target molecule or steric hindrance, causing a reduction in the hybridization efficiency in a probe-binding site-specific way [37].

The signal intensities of the individual hybridizations were found to vary significantly for the different probes spotted on the microarray. This is an expected consequence of using the one set of hybridization conditions to evaluate many different probes on a microarray and has been reported by others [21,31]. The positioning of the oligonucleotide probe sequence on the 16S rRNA gene is important and can determine the strength of hybridization signal obtained, firstly because every nucleic acid binds in a defined orientation to its complement, and secondly because certain regions of the gene are less accessible to probe binding due to the secondary structure of the gene [37]. Other possible explanations for the difference in signal intensities include different probe melting temperatures, varying $\mathrm{dG}$ values of secondary structure formations of probes, and different lengths of oligonucleotide probes.

The detection sensitivity of PCR-amplified organisms with the COMPOCHIP was determined in a previous study [18] and the detection limit of the probes tested was found to be approximately $10^{3}$ cells, or $5 \%$ of the total microbial population. It must however be considered that the sensitivity limits for different probes vary due to the ability of certain probes to give higher signal intensities than others. It is also possible that a detection limit of 5\% will allow potential pathogens to go undetected by the COMPOCHIP microarray.

\section{COMPOCHIP Analyses of Compost Samples}

The aim of designing the COMPOCHIP 16S rRNA gene microarray was to develop a tool for detecting the presence of different bacteria in a particular environmental sample in a single test. Composts contain a large and diverse community of microorganisms that are involved in the digestion of organic wastes. When the nucleic acids of pure bacterial cultures are examined with a microarray, unam- 
biguous hybridization patterns are generally observed. However, when microarrays are used to evaluate environmental samples, the relative abundance of various target and closely related non-target microorganisms can be more difficult to determine due to the complexity of natural communities and potential cross-hybridization events [17]. For this reason, more significance to the presence of certain bacteria in different samples was attributed when more than one of the probes specific for a particular target was positive.

Due to a potential bias that may be introduced by PCR [44], the results obtained by hybridizing PCR-amplified templates may reflect a biased microbial community composition [51]. However, the use of PCR to amplify target DNA greatly increases the detection sensitivity of microorganisms in an environmental sample in comparison to non-PCR-based methods. This was especially important in this study, as we are interested in the presence of different bacteria, which may be present in relatively low numbers, yet still be of importance. Without PCR, it is possible that the levels of such microorganisms would be too low for detection.

Due to the known difficulties associated with working with compost and with obtaining sample homogeneity, bulk samples were carefully prepared for this study. According to Dionisi et al. [15], PCR amplification is responsible for a greater variability in results than DNA extraction. These authors found that DNA extraction contributed little to variability, as determined by real-time PCR. We thus decided not to conduct replicate DNA extractions. In order to reduce bias, three replicate PCR amplifications were conducted on bulk compost sample DNAs. The COMPO CHIP microarray was applied to the three compost types (green, manure mix, and anaerobic digestate composts), each sampled at different maturity stages $(2,8$, and 16 weeks), so to determine if the array was able to discriminate between the various composts and to determine which bacteria were present in each of them. Because a linear correlation between signal intensity of a particular probe and target concentration has been reported by others $[45,48]$, the results obtained with the COMPOCHIP microarray were analyzed semi-quantitatively. However, because different probes have different affinities for their targets and because of the inherent bias involved with PCR, the information on the relative abundance of different microorganisms derived from the microarrays needs to be interpreted with some caution.

Figure 1 shows a heat map containing the hybridization results of probes for which the highest SNR for all the samples tested was $\geq 2$. Probes for which all samples gave SNR values $<2$ were negative and not considered to be useful in the differentiation of compost samples. Interestingly, the 2-week composts were found to have the highest
Figure 1 Visualization of microarray results for all composts. The probe names are listed in each row, and columns represent the different samples. The SNR values for all probes were normalized to the UNIV 1389 probe, and attributed a value between 0 and 1 (UNIV $1389=1$ ). The relative intensity of the normalized SNR signal of probes is indicated by the colour bar. Only probes which had a maximum signal for all hybridizations above the threshold value of 2 were included in the table

number and greatest intensity of signals (indicated by darker colors in the heat map) when compared with the 8and 16-week compost samples (Fig. 1). In the green compost, there were 28 probes with normalized signals above 0.03065 in the 2 -week compost, while only ten probes with signals above this value in the 16-week sample. In the anaerobic digestate and manure mix composts, there were 34 and 43 probes with normalized signals above 0.03065 in the 2-week compost, respectively, and only seven and five probes with signals above this value in the 16-week sample, respectively. In the 8- and 16-week manure mix compost samples, the only signals were from probes targeting groups (e.g., Alphaproteobacteria, Low $\mathrm{G}^{+}$ $\mathrm{C}$ bacteria), and there were no signals from probes targeting individual species. It is possible that the probes on the array are biased toward bacteria that are more commonly found in earlier composting stages rather than in later stages. For this reason, the diversity in the more mature composts may be under-represented by the array. It is also possible that microorganisms targeted by probes on the array were present in the compost samples but at levels below the detection limit of the microarray.

\section{Detection of Different Microorganisms}

Bacteria belonging to the genus Actinomyces were found to be present in high numbers in all the different compost types (Fig. 1). In the green compost, Actinomyces levels were higher in the mature compost than in the fresher compost samples. These results are supported by previous findings, whereby Actinomyces have been reported to develop more slowly than most other microorganisms and are thus comparatively ineffective competitors under highnutrient conditions [24, 38]. The presence of Actinomyces in composts has been reported to be desirable due to several positive effects exerted by members of the genus, among which is the ability to produce various antibiotics that can suppress pathogenic microorganisms.

The green composts were also found to have the highest levels of Chryseobacterium (Fig. 1). Three Chryseobacterium probes were included on the array, and although not all the probes worked equally well, all probes resulted in hybridization and SNR values above the threshold. For all the composts, Chryseobacterium levels were higher in the fresher composts than in the more mature composts. 


\begin{tabular}{|c|c|c|c|c|c|c|c|c|c|c|c|}
\hline & & \multicolumn{3}{|c|}{ GREEN } & \multicolumn{3}{|c|}{ ANAEROBIC DIGESTATE } & \multicolumn{3}{|c|}{ MANURE MIX } & \\
\hline & & 2 & 8 & 16 & 2 & 8 & 16 & 2 & 8 & 16 & \\
\hline \begin{tabular}{|l} 
Acidobacterium \\
Acinetobacter \\
Acinetobacter calcoaceticus \\
Acinetobacter calcoaceticus \\
Acinetobacter calcoaceticus \\
Acinetobacter lofofii \\
Acinetobacter lwofii \\
Actinomadura \\
Actinomyces \\
\end{tabular} & \begin{tabular}{|l} 
KO465 \\
KO252 \\
KO254 \\
KO340 \\
KO341 \\
KO253 \\
KO233 \\
KO467 \\
KO268 \\
\end{tabular} & & 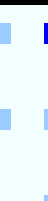 & $\square$ & & & & & & & $\begin{array}{l}0,61305-1 \\
0,30553-0,01305 \\
0,12261-0,030653 \\
0,061131-0,12261 \\
0,030365-0,06131 \\
0-0,03065\end{array}$ \\
\hline
\end{tabular}

Actinomyces

Actinomyces

Aeromonas hydrophila A

Agrobacterium tumefaciens

Agrobacterium tumefaciens

\begin{tabular}{l|l} 
Alcaligenes defragrans, faecalis & $\mathrm{KO} 34$ \\
\hline
\end{tabular}

Alcaligenes faecalis

Alpha pro

\begin{tabular}{l|l} 
Archaea & KO24 \\
\hline Arthrobacter/Micrococcus & KO31 \\
\hline
\end{tabular}

Azospirillum lipoferoccus

Azotobacter beijerincki

Azotobacter probe

Bacillus badius

Bacillus pumilus

Bacilus smithii

Bacillus subtilis

Bacillus thermodenitrificans

Bacteroides

Bacteroides/Prevotella

Brevibacillus

Burkholderia cepacia

Burkholderia

Campylobacter jejuni

Cellulophaga

Chryseobacterium

\begin{tabular}{l|l}
\hline Chryseobacterium & KO49 \\
\hline Chryseobacterium & KO49 \\
\hline Cl. proteolyticum, limosum, histolyticum & KO26 \\
\hline
\end{tabular}

\begin{tabular}{ll}
\hline Clostridium fallax, perfringens & $\mathrm{KO} 26$ \\
\hline
\end{tabular}

Comomonas denititrificans

Enterobacteriaceae D

Enterococcus

\begin{tabular}{l|l}
\hline Enterococcus/Lactobacillus & KO38 \\
\hline EUB338II & KO28 \\
\hline EUB338III & KO29 \\
\hline
\end{tabular}

Listeria monocytogenes

Low $\mathrm{G}+\mathrm{C}$

Methylobacterium

Microbacterium

Microbacterium

Microbacterium

Neisseria meningitidis

Nitrosomonas europa

Nitrosomonas nitrosa

\begin{tabular}{l} 
Nitrosomonas oligotropha \\
\hline Nitrosomonas oligotropha
\end{tabular}

Nitrosomonas ureae

Nitrosomonas ureae

\begin{tabular}{l|l}
$\mathrm{KO}$ & $\mathrm{KO} 31$ \\
$\mathrm{KO} 2$ \\
\hline
\end{tabular}

\begin{tabular}{ll} 
Nitrospira/Nitrosovibrio/Nitrosomonas & KO295 \\
\hline
\end{tabular}

\begin{tabular}{l|l} 
Nitrospira/Nitrosovibrio/Nitrosomonas & $\mathrm{KO} 294$ \\
\hline & $\mathrm{KO}$
\end{tabular}

Paenibacillus macerans

\begin{tabular}{l|l}
\hline KO432 \\
\hline Propionibacterium & KO32 \\
\hline
\end{tabular}

Pseudomonas

$\frac{\text { Pseudomonas }}{\text { Pseudomonas }}$

\begin{tabular}{l|l}
\hline Pseudomonas & KO5 \\
\hline Pseudomonas aeruginosa & KO12 \\
\hline
\end{tabular}

Pseudomonas aeruginosa

\begin{tabular}{|l|l}
\hline Pseudomonas aeruginosa & KO4 \\
\hline Pseudomonas fluorescens & KO5 \\
\hline
\end{tabular}

\begin{tabular}{l} 
Phodococcus/Mycobacterium/Nocardia KO54 \\
\hline
\end{tabular}

Saccharomonospora

\begin{tabular}{|l|l}
\hline Salmonella & KO2 \\
\hline Salmonella & KO4 \\
\hline
\end{tabular}

Sphingobacterium

Sphingobacterium

Sphingobacterium

\begin{tabular}{l|l} 
Sphingobacterium & KO549 \\
\hline Sphingobacterium & KO548 \\
\hline Sphingobacterium & KO551 \\
\hline Stenotrophomonas maltophilia & KO443 \\
\hline
\end{tabular}

\begin{tabular}{ll} 
Stenotrophomonas maltophilia & $\mathrm{KO} 243$ \\
\hline
\end{tabular}

Thermoactinomyces

Thermoactinomyces

Thermoactinomyces

Thermoactinomyces

Thermocrispum agreste/municipal $\mathrm{KO} 338$

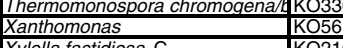

\begin{tabular}{l|l} 
Xylella fastidiosa C & KO210 \\
\hline$X y l e l l$ & Kanthomonas/Stenotroph \\
\hline
\end{tabular}

Xylella/Xanthomonas/StenotrophdKO241
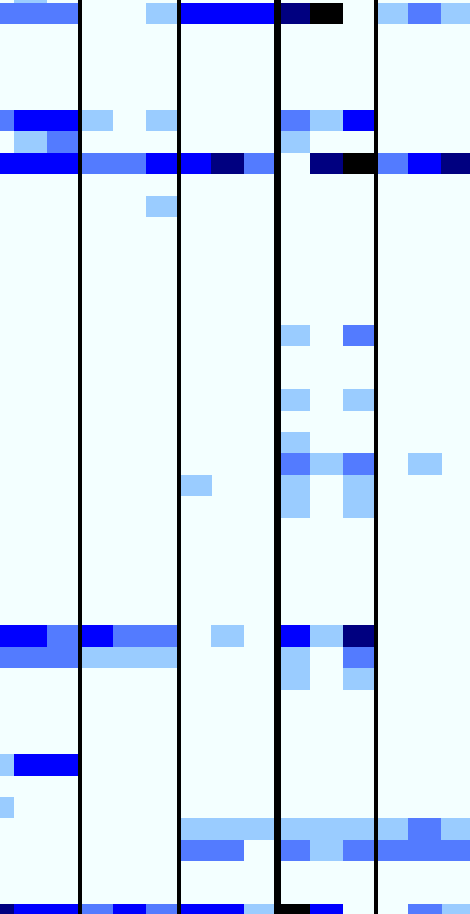

(n)

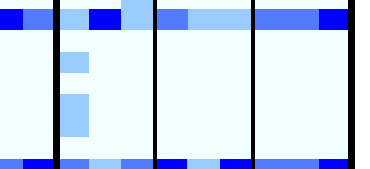

0,03065 
Chryseobacterium belongs to the phylum Bacteroidetes, members of which are known for their importance in the degradation of complex biopolymers in composting situations [1].

Higher signals for the probes targeting Microbacterium and Sphingobacterium were also detected in the 2-week composts and for the green compost in particular. The group probes targeting the genera Xylella, Xanthomonas, and Stenotrophomonas hybridized well with all 2-week composts and with the 16-week green compost. These bacterial genera include species that are involved in plant disease suppression and are also known as plant and human pathogens [23]. The presence of these bacteria could be of concern in a mature compost product. Probes targeting the grape pathogen Xylella fastidiosa did not hybridize with any target DNA from these composts. Of the five probes targeting Xanthomonas (a genus comprising many plant pathogens), only one probe produced a detectable hybridization signal. As all five probes were found to work well with a pure culture of Xanthomonas, it can be concluded that either very low levels of Xanthomonas were present in the composts or that the hybridization with the KO 561 probe was due to a non-specific hybridization with other DNA. The much lower SNRs obtained for this probe in the 16-week compost samples (all below the threshold value of 2) indicate a reduction or elimination of this potential pathogen during the composting process. On the other hand, probes targeting Stenotrophomonas maltophilia (KO 243 and KO 443), an organism well known for its involvement in plant disease suppression [25], gave detectable signals with all the compost types. DNA from $S$. maltophilia may have been responsible for the significant SNR values seen for the group probe.

The COMPOCHIP microarray included probes targeting known plant disease suppressive (PDS) bacteria (Bacillus subtilis, Bacillus pumilus, Burkholderia cepacia, Paenibacillus, Pseudomonas fluorescens, Pseudomonas putida, Pseudomonas stutzeri, S. maltophilia, and Streptomyces; Electronic supplementary material, Table 1). With the exception of $P$. stutzeri, $P$. putida, and Streptomyces, which were not found in any compost samples, probes targeting the other PDS bacteria were found to hybridize with DNA from various samples, indicating the presence of such microorganisms in the composts. Higher levels of the PDS bacteria were found in the fresher composts. A study was conducted by Nakasaki et al. [36] with the purpose of producing compost capable of consistently suppressing Rhizoctonia large patch on mascarene grass. The authors found that by inoculating the suppressive bacterium in the initial stage of composting, after heating the compost to $80^{\circ} \mathrm{C}$, the suppressive bacteria could grow sufficiently well to form spores. Without this inoculation step, it was not possible to foster high concentrations of disease-suppres- sive bacteria in compost because of the concentration of other bacteria originally present in the raw material.

Low signals were obtained for the Archaea probe KO 31 upon hybridization of compost DNAs. These results must clearly be due to cross-hybridization events, as hybridizations were conducted with PCR products generated using bacterial primers, and thus, it should only be bacterial DNAs yielding signals upon hybridization. Cross hybridization with Archaea probes has also been reported by Eyers et al. [17].

No signals were obtained for probes for most of the pathogens included on the array. Probes targeting the plant pathogens Erwinia amylovora, Pantoea, Azospirillum brasilense, Acidovorax avenae, Ralstonia solanacearum, and Pseudomonas syzygii gave no signals upon hybridization. Similarly, probes targeting the species Vibrio cholerae, Helicobacter pylori [5], and Staphylococcus aureus, and genera including the human pathogens Nocardia, Streptococcus, and Clostridium (with the exception of the probes KO 260 and KO 264, likely to be false positive reactions) gave no signals upon hybridization. This would indicate that the different composts do not contain these organisms or, if they do, that the organisms are present at levels below the detection limit.

\section{Multivariate Analysis of Microarrays}

Probes providing little or no information, as indicated by a SNR $<2$, were not included in analyses. The universal bacterial probes KO 27 (EUB 338) and KO 32 (UNIV 1389) [4] were also excluded from the analyses, as these probes bound all bacteria and thus did not allow differentiation of microbial communities between samples. One hundred probes were included in the analyses. An average value for the two duplicate probe spots was calculated for each of the three replicate arrays. Covariance-based redundancy analysis was conducted. Figure 2 shows a canonical analysis loading plot; the two axes explain $70.4 \%$ of variance, the first axis representing $51.2 \%$ of the variance, the second axis representing 19.2\%. Multivariate analysis showed that the bacterial community compositions of the three composts were different at the beginning of the composting process. The 2-week compost samples appeared to differ significantly from each other, being plotted in different areas of the ordination graph. However, over time, the bacterial communities became more similar. This can be seen by the 16-week compost samples clustering together. The replicates of the compost samples were found to group closely together. The 2-week green compost sample was found to be the most different of all the compost samples, based on the microarray results. This is not surprising, as the other two composts were more similar in nature, both having undergone anaerobic diges- 
Figure 2 Loading plot obtained by redundancy analysis, depicting the organisms responsible for community differences amongst the composts. The figure shows the development over time of the three compost types. The numbers 2,8 and 16 represent the number of weeks of composting, and the vectors show the covariance structure of the probe signals. The two axes represent $70.4 \%$ of the explained variance

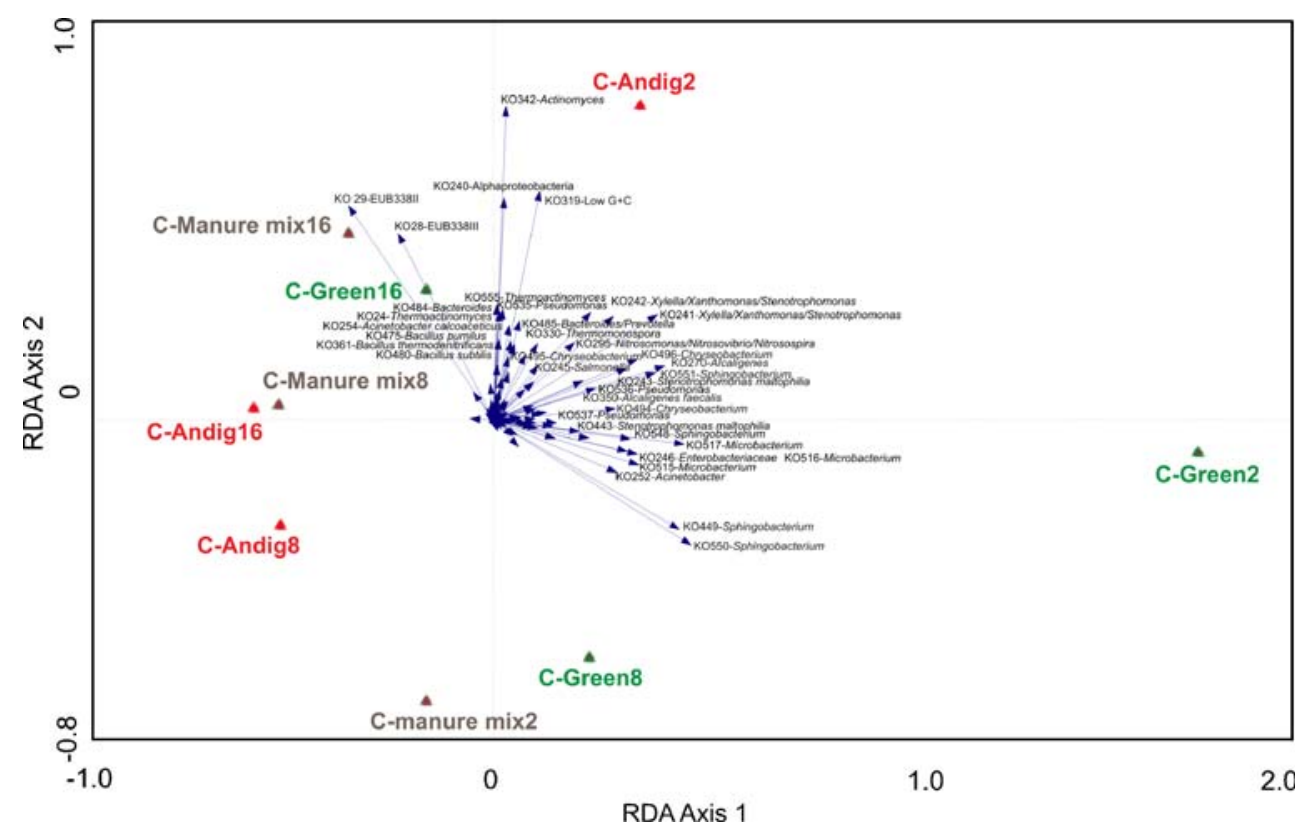

tion processes prior to composting (partly or fully), which inhibit and enhance the growth and survival of different microorganisms (the manure mix compost comprised $25 \%$ horse manure).

The loading plot (Fig. 2) shows the probes that were responsible for community differences among the composts. The lengths of the arrows indicate the significance for compost differentiation. Arrows of probes point in the direction of samples with above-average signal, and probes with similar arrow directions have high covariance, meaning they tend to occur jointly on the microarrays. The Sphingobacterium genus probes KO 548, KO 549, and KO 550 were found to give high signals in the less-mature green composts ( 2 and 8 weeks) and manure mix compost. Sphingobacterium is an aerobic bacterium, known to frequently occur in compost [27]. The incidence of
Sphingobacterium in the anaerobic digestate composts was lower. There was also a higher association between the presence of Microbacterium (probes KO 515, 516, and 517) and the less-mature green and manure mix composts. The Actinomyces KO 342, Low G+C, and Alphaproteobacteria probes correlated well with the mature (16 weeks) green and manure mix composts, as well as with the immature ( 2 weeks) anaerobic digestate compost. Overall, there did not appear to be above-average incidences of probes with the compost samples located more in the left-hand side of the canonical plot, mostly either the 8- or 16-week samples and also in the 2-week manure mix compost. However, the EUB 338II and EUB 338III probes specific for the Planctomycete and Verrucomicrobia groups respectively [12], did correlate well with the older composts and would appear to be indicator probes for more mature composts.
Figure 3 Cluster analysis of DGGE fingerprints based on 16S rDNA extracted and amplified from green, manure mix and anaerobic digestate composts at 2, 8 and 16 weeks of composting. Values at the branches of the dendrogram indicate the percentage of similarity, based on the Dice correlation coefficient

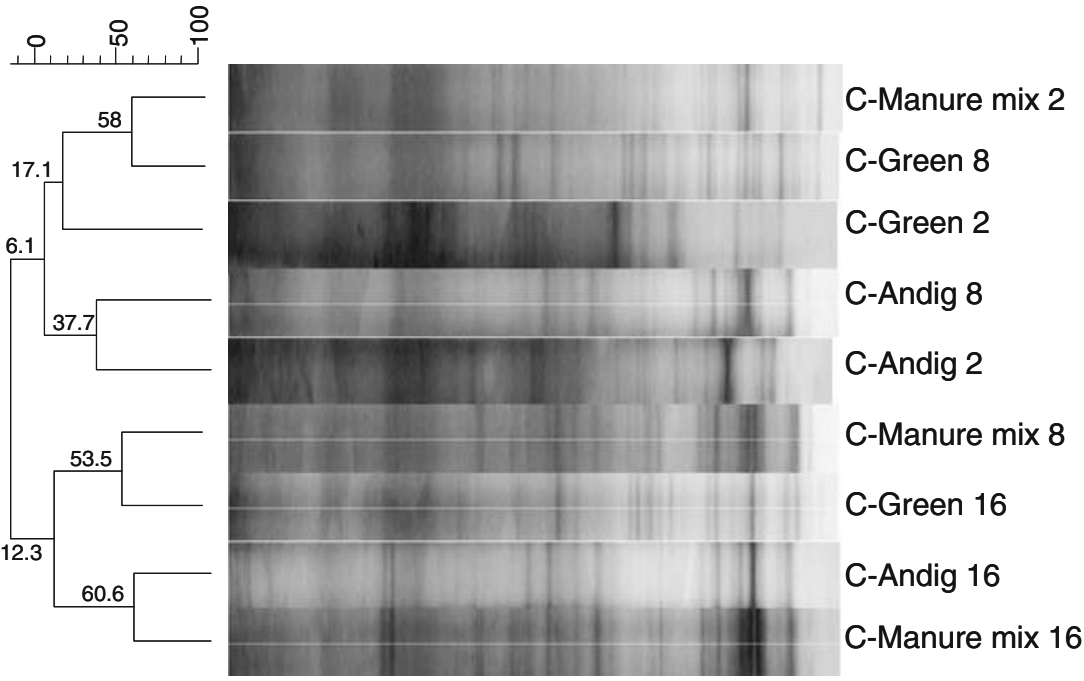




\section{PCR-DGGE Analyses of Compost Samples}

In order to compare the newly developed COMPOCHIP microarray with a method that has been frequently used to study microbial community composition of complex habitats, PCR-DGGE analysis was performed. For the DGGE analysis, DNA of all three compost types was used to obtain the banding patterns of the contained microbial communities. Cluster analysis of the 16S rRNA gene-based banding patterns revealed that the age of the composts had more influence on the contained microbial community structure than the compost type (Fig. 3). Furthermore, the three different compost types became more similar over time, suggesting that the mature composts had more bacterial species in common than did the starting material. This is in accordance to the microarray data, which showed the same overall results.

\section{Conclusions}

This study has resulted in the development of the COMPOCHIP microarray, which contains probes targeting microorganisms that have been previously reported in the composting process, as well as plant, animal, and human pathogens and plant disease suppressive bacteria. The array has been tested with pure cultures of microorganisms and has been shown to work well with only a low percentage of non-specific hybridizations (false positive, $0.62 \%$; false negative, $0.07 \%$ ). Using the COMPOCHIP microarray, it was possible to discriminate between different compost types and composts of different ages. Using a multivariate redundancy analysis, it was found that the younger 2-week composts were distinct from each other in terms of the bacterial communities, while the more mature 16-week composts were similar. The array also indicated that particular probes (targeting Sphingobacterium, Actinomyces, Xylella/Xanthomonas/Stenotrophomonas, Microbacterium, Verrucomicrobia, Planctomycetes, Low $\mathrm{G}+\mathrm{C}$, and Alphaproteobacteria) were more important in discriminating between different composts. The results of DGGE correlated well with the results of the microarrays in showing differences in amplicon sequences between the different compost samples. It must however also been mentioned that the array only targeted known compost microorganisms, and as such, it is possible that microorganisms with no cultured members may have been performing important roles in the composting process, yet going undetected. Clone library studies may reveal the identity of as yet unknown and uncultured composting microorganisms, to which probes could be designed in the future.

This manuscript describes the design, development, and application of the COMPOCHIP microarray and has demonstrated the huge potential of microarrays to analyze the bacterial communities of different environmental samples in a single test. More comprehensive sequence-based assessment of the microbial diversity associated with the different phases of the composting process is needed and will allow the design of more probes and the expansion of the COMPOCHIP microarray. Application of the microarray should allow for better compost process management in the future and the tracing of compost amendments to soils.

Acknowledgments The authors would like to thank Michael Rudnicki and his laboratory at the Department of Nephrology, Medical University of Innsbruck for the use of the Microarray scanning equipment. Thanks also go to Alice Wallner, Austrian Agency for Health and Food Safety, AGES, for providing bacterial strains and to Thomas Kupper and Rahel Brändli (Ecole Polytechnique Fédérale from Lausanne, EPFL, Switzerland) for their collection of compost samples. The critical reviewing of the manuscript by Marta Goberna is also acknowledged. The project was funded by the Fonds zur Förderung der wissenschaftlichen Forschung (FWF) Austria, P-15694, and by the Tiroler Wissenschaftsfonds.

\section{References}

1. Alfreider A, Peters S, Tebbe CC, Rangger A, Insam H (2002) Microbial community dynamics during composting of organic matter as determined by $16 \mathrm{~S}$ ribosomal DNA analysis. Compost Sci Util 10:303-312

2. Alm EW, Oerther DB, Larsen N, Stahl DA, Raskin L (1996) The oligonucleotide probe database. Appl Environ Microbiol 62:3557-3559

3. Altschul SF, Gish W, Miller W, Myers EW, Lipman DJ (1991) Basic local alignment search tool. J Mol Bio 215:403-410

4. Amann R, Binder BJ, Olson RJ, Chisholm SW, Devereux R, Stahl DA (1990) Combination of 16S rRNA-targeted oligonucleotide probes with flow cytometry for analyzing mixed microbial populations. Appl Environ Microbiol 56:1919-1925

5. Barrett DM, Flaigel DO, Metz DC, Montone K, Furth EE (1997) In situ hybridization for Helicobacter pylori in gastric mucosal biopsy specimens: quantitative evaluation of test performance in comparison with the CLOtest and thiazine stain. J Clin Lab Anal 11:374-379

6. Beffa T, Blanc M, Lyon P-F, Vogt G, Marchiani M, Lott Fischer J, Aragno M (1996) Isolation of Thermus strains from hot composts (60 to $80{ }^{\circ} \mathrm{C}$ ). Appl Environ Microbiol 62:1723-1727

7. Blanc M, Marilley L, Beffa T, Aragno M (1999) Thermophilic bacterial communities in hot composts as revealed by most probable number counts and molecular (16S rDNA) methods. FEMS Microbiol Ecol 28:141-149

8. Bodrossy L, Sessitsch A (2004) Oligonucleotide microarrays in microbial diagnostics. Curr Opin Microbiol 7:246-255

9. Bodrossy L, Stralis-Pavese N, Murrell JC, Radajewski S, Weilharter A, Sessitsch A (2003) Development and validation of a diagnostic microbial microarray for methanotrophs. Environ Microbiol 5:566-582

10. Breslauer KJ, Frank R, Blocker H, Marky LA (1986) Predicting DNA duplex stability from the base sequence. Proc Natl Acad Sci USA 83:3746-3750

11. Buchholz-Cleven BEE, Rattunde B, Straub KL (1997) Screening for genetic diversity of isolates of anaerobic Fe(II)-oxidizing 
bacteria using DGGE and whole-cell hybridization. Syst Appl Microbiol 20:301-309

12. Daims H, Brühl A, Amann R, Schleiffer K-H, Wagner M (1999) The domain-specific probe EUB338 is insufficient for the detection of all Bacteria: development and evaluation of a more comprehensive probe set. Syst Appl Microbiol 22:434-444

13. Danon M, Franke-Whittle I, Insam H, Chen Y, Hadar Y (2008) Molecular analysis of bacterial community succession during prolonged compost curing. FEMS Microbiol Ecol 65:133-144

14. Dees PM, Ghiorse WC (2001) Microbial diversity in hot synthetic compost as revealed by PCR-amplified rRNA sequences from cultivated isolates and extracted DNA. FEMS Microbiol Ecol 35:207-216

15. Dionisi HM, Harms G, Layton AC, Gregory IR, Parker J, Hawkins SA, Robinson KG, Sayler GS (2003) Power analysis for real-time PCR quantification of genes in activated sludge and analysis of the variability introduced by DNA extraction. Appl Environ Microbiol 69:6597-6604

16. Elorrieta MA, Suarez-Estrella F, Lopez MJ, Vargas-Garcia MC, Moreno J (2003) Survival of phytopathogenic bacteria during waste composting. Agric Ecosyst Environ 96:141-146

17. Eyers L, Stenuit B, El Fantroussi S, Agathos SN (2003) Microbial Ecology of TNT-contaminated soils and anaerobic TNT biodegradation processes. In: Proceedings of the 103rd general meeting of the American Society for Microbiology, Washington DC

18. Franke-Whittle IH, Klammer SH, Insam H (2005) Design and application of an oligonucleotide microarray for the investigation of compost microbial communities. J Microbiol Meth 62:37-56

19. Franke-Whittle IH, Klammer SH, Mayrhofer S, Insam H (2006) Comparison of different methods for the production of labeled target DNA for microarray hybridization. J Microbiol Meth $65: 117-126$

20. Fuchs JG (2002) Practical use of quality compost for plant health and vitality improvement. In: Insam $\mathrm{H}$, Riddech $\mathrm{N}$, Klammer S (eds) Microbiology of composting. Springer-Verlag, Berlin, pp 435-444

21. Guschin D, Mobarry B, Proudnikov D, Stahl D, Rittmann B, Mirzabekov A (1997) Oligonucleotide microchips as genosensors for determinative and environmental studies in microbiology. Appl Environ Microbiol 63:2397-2402

22. Haruta S, Kondo M, Nakamura K, Chanchitpricha C, Aiba H, Ishii M, Igarashi Y (2004) Succession of a microbial community during stable operation of a semi-continuous garbage-decomposing system. J Biosci Bioeng 98:20-27

23. Hogardt M, Trebesius K, Geiger AM, Hornef M, Rosenecker J, Heesemann J (2000) Specific and rapid detection by fluorescent in situ hybridisation of bacteria in clinical samples obtained from cystic fibrosis patients. J Clin Microbiol 38:818-825

24. Hoitink HAJ, Boehm MJ (1999) Biocontrol within the context of soil microbial communities: A substrate-dependent phenomenon. Annu Rev Phytopath 37:427-446

25. Hoitink HAJ, Fahy PC (1986) Basis for the control of soilborne plant pathogens with composts. Annu Rev Phytopath 24:93-114

26. Hoitink HAJ, Stone AG, Han DY (1997) Suppression of plant diseases by compost. HortScience 32:184-187

27. Kim K-H, Ten LN, Liu Q-M, Im W-T, Lee S-T (2006) Sphingobacterium daejeonense sp. nov., isolated from a compost sample. Int J Syst Evol Microbiol 56:2031-2036

28. Koizumi Y, Kelly JJ, Nakagawa T, Urakawa H, El-Fantroussi S, Al-Muzaini S, Fukui M, Urushigawa Y, Stahl DA (2002) Parallel characterization of anaerobic toluene- and ethylbenzene-degrading microbial consortia by PCR-denaturing gradient gel electrophoresis, RNA-DNA membrane hybridization, and DNA microarray technology. Appl Environ Microbiol 68:3215-3225

29. Lee D-Y, Shannon K, Beaudette LA (2006) Detection of bacterial pathogens in municipal wastewater using an oligonucleotide microarray and real-time quantitative PCR. J Microbiol Meth 65:453-467

30. Legendre P, Legendre L (1998) Numerical ecology. Elsevier Science BV, Amsterdam

31. Liu W-T, Mirzabekov AD, Stahl DA (2001) Optimization of an oligonucleotide microchip for microbial identification studies: a non-equilibrium dissociation approach. Environ Microbiol 3:619629

32. Loy A, Horn M, Wagner M (2003) ProbeBase: an online resource for rRNA-targeted oligonucleotide probes. Nucleic Acids Res 31:514-516

33. Loy A, Lehner A, Lee N, Adamczyk J, Meier H, Ernst J, Schleifer $\mathrm{K}-\mathrm{H}$, Wagner M (2002) Oligonucleotide microarray for 16S rRNA gene-based detection of all recognized lineages of sulfate-reducing prokaryotes in the environment. Appl Environ Microbiol 68:5064-5081

34. Ludwig L, Strunk O, Westram R, Richter L, Meier H, Yadhukumar A, Buchner A, Lai T, Steppi S, Jobb G, Foerster W, Brettske I, Gerber S, Ginhart AW, Gross O, Grumann S, Hermann S, Jost R, Koenig A, Liss T, Lussmann R, May M, Nonhoff B, Reichel B, Strehlow R, Stamatakis A, Stuckmann N, Vilbig A, Lenke M, Ludwig T, Bode A, Schleifer K-H (2004) ARB: a software environment for sequence data. Nucleic Acids Res 32:1363-1371

35. Muyzer G, de Waal EC, Uitterlinden AG (1993) Profiling of complex microbial populations by denaturing gradient gel electrophoresis analyses of polymerase chain reaction-amplified genes for 16S rRNA. Appl Environ Microbiol 59:695-700

36. Nakasaki K, Hiraoka S, Nagata H (1998) A new operation for producing disease-suppressive compost from grass clippings. Appl Environ Microbiol 64:4015-4020

37. Peplies J, Glockner FO, Amann R (2003) Optimization strategies for DNA microarray-based detection of bacteria with 16S rRNAtargeting oligonucleotide probes. Appl Environ Microbiol 69:1397-1407

38. Ryckeboer J, Mergaert J, Vaes K, Klammer S, De Clercq D, Coosemans J, Insam H, Swings J (2003) A survey of bacteria and fungi occurring during composting and self-heating processes. Ann Microbiol 53:349-410

39. Sanguin H, Herrera A, Oger-Desfeux C, Dechesne A, Simonet P, Navarro E, Vogel T, Moenne-Loccoz Y, Xavier N, Grundmann GL (2006) Development and validation of a prototype 16S rRNAbased taxonomic microarray for Alphaproteobacteria. Environ Microbiol 8:289-307

40. Schloss P, Hay AG, Wilson DB, Gossett JM, Walker LP (2005) Quantifying bacterial population dynamics in compost using $16 \mathrm{~S}$ rRNA gene probes. Appl Microbiol Biotechnol 66:457-463

41. Schwieger F, Tebbe CC (1998) A new approach to utilize PCRsingle-strand conformation polymorphism for 16S rRNA genebased microbial community analysis. Appl Environ Microbiol 64:4870-4876

42. Stahl DA, Amann R (1991) Development and application of nucleic acid probes in bacterial systematics. In: Stackebrandt E, Goodfellow M (eds) Nucleic acid techniques in bacterial systematics. John Wiley, Sons, Chichester, England, pp 205-248

43. Stralis-Pavese N, Sessitsch A, Weilharter A, Reichenauer T, Riesing J, Csontos J, Murrell JC, Bodrossy L (2004) Optimization of diagnostic microarray for application in analysing landfill methanotroph communities under different plant covers. Environ Microbiol 6:347-363

44. Suzuki MT, Giovannoni SJ (1996) Bias caused by template annealing in the amplification of mixtures of $16 \mathrm{~S}$ rRNA genes by PCR. Appl Environ Microbiol 62:625-630

45. Taroncher-Oldenburg G, Griner EM, Francis CA, Ward BB (2003) Oligonucleotide microarray for the study of functional gene diversity in the nitrogen cycle in the environment. Appl Environ Microbiol 69:1159-1171 
46. ter Braak CJF, Šmilauer P (2002) CANOCO Reference Manual and CanoDraw for Windows User's Guide: Software for Canonical Community Ordination (version 4.5). Microcomputer Power, Ithaca

47. Tiquia SM (2005) Microbial community dynamics in manure composts based on 16S and 18S RDNA T-RFLP profiles. Environ Technol 26:1101-1113

48. Tiquia SM, Wu L, Chong SC, Passovets S, Xu D, Xu Y, Zhou J (2004) Evaluation of 50-mer oligonucleotide arrays for detecting microbial populations in environmental samples. Biotechniques $36: 664-675$
49. Urakawa H, Noble PA, El Fantroussi S, Kelly JJ, Stahl DA (2002) Single-base-pair discrimination of terminal mismatches by using oligonucleotide microarrays and neural network analyses. Appl Environ Microbiol 68:235-244

50. Varani G (1995) Exceptionally stable nucleic acid hairpins. Annu Rev Biophys Biomol Struct 24:379-404

51. von Wintzingerode F, Gobel UB, Stackebrandt E (1997) Determination of microbial diversity in environmental samples: Pitfalls of PCR-based rRNA analysis. FEMS Microbiol Rev 21:213-229 